
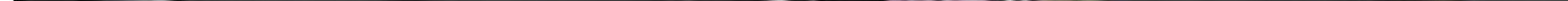


\section{UNA APROXIMACIÓN SEMIÓTICA AL USO NARRATIVO DEL PRODUCT PLACEMENT COMO MOMENTO DE CONSUMO PRESENTE EN LA TELENOVELA PERUANA}

\section{A semiotic approach to the narrative use of Product Placement as a moment of consumption present in the Peruvian soap opera}

iD Eduardo Enrique Yalán-Dongo, docente e investigador, Universidad de Lima y Universidad peruana de ciencias aplicadas. (Perú) (eyalan@ulima.edu.pe)

(https://orcid.org/0000-0002-0143-4973)

\section{Resumen}

La telenovela peruana es uno de los principales formatos narrativos de la televisión peruana. Actualmente, el desarrollo de su relato ha motivado mayor participación de marcas globales que buscan promover sus productos en vista de que existe un público fiel, capturado por el tono cómico con el que se presentan diversas temáticas sociales en la telenovela (discriminación, machismo, identidad de clase). A partir de esta perspectiva, el presente artículo pretende identificar la inserción del product placement en la narrativa de la telenovela peruana. Nos ocuparemos concretamente de aquellas presentaciones que se postulan como presencias orgánicas en el relato. Estamos interesados en observar particularmente la forma de la telenovela "Los Vílchez" producida por América Tv durante el año 2019 lo que permitió trabajar un nivel comercial camuflado orgánicamente en su trama narrativa. Se han escogido para este estudio escenas específicas de inserción del product placement en la trama para analizar las interacciones del público desde una perspectiva narrativo-semiótica.

\section{Palabras clave}

Product placement, narrativa, telenovela, semiótica

Keywords

narrative, soap opera, semiotics.

\begin{abstract}
The Peruvian telenovela is one of the main narrative formats of Peruvian television. Currently, the development of its story has motivated greater participation of global brands that seek to promote their products in view of a loyal audience, captured by the comic tone with which various social themes are presented in the telenovela (discrimination, machismo, class identity). From this perspective, this article aims to identify the insertion of the product placement in the narrative of the Peruvian soap opera, specifically dealing with those presentations that are postulated as organic presences to the story. We are particularly interested in observing how the telenovela "Los Vílchez" produced by América Tv during 2019 allows us to work on a commercial level organically camouflaged in its narrative plot. Specific scenes of insertion of the product placement in the plot have been chosen for this study to analyze the interactions of the public from a narrative-semiotic perspective.
\end{abstract}


1.

\section{Introducción}

Siendo un producto nacido en Latinoamérica para su difusión masificada (Alfaro, 2016), la telenovela ha persistido como una de las formas más importantes de expresión cultural. En Latinoamérica, sus registros sobresalen en países como Colombia, Brasil, Chile, México, Argentina y Perú con producciones como "Betty la fea" (Colombia), "Pasión de Gavilanes" (Colombia), "La esclava Isaura" (Brasil), "Montecristo" (Argentina), "Amar a muerte" (México) y "Al fondo hay sitio" (Perú). Teniendo en cuenta los procesos sociopolíticos álgidos de muchos países latinoamericanos en las últimas décadas (Corruptela política, militarismo estatal, enfrentamiento con movimientos terroristas) la telenovela se ha revelado como el relato que ha transparentado una agrietada idiosincrasia, álgidas atmósferas culturales y situadas crisis políticas. Esto no quiere decir que las narrativas de las telenovelas reproducen únicamente concepciones culturales, sino también registran las huellas de pretensiones comerciales que se encuentran inmiscuidas en el desarrollo del melodrama. Desde una perspectiva mercantil, la telenovela es el relato de alcance masivo ideal para las marcas porque permite ser la vitrina de propuestas comerciales en tanto sus narrativas no son invasivas para el público objetivo. De esta manera, la narrativa de la telenovela no solo cobra sentido porque se encuentra endosada a lo social, también se construye como un ideal colectivo que permite normalizar el consumo, dosificar a los objetos mercantiles.

Actualmente, el desarrollo del relato melodramático en el Perú ha motivado mayor participación de marcas globales que buscan promover sus productos en vista de que existe un público fiel, capturado por el tono cómico con el que se presentan diversas temáticas sociales en la telenovela (discriminación, machismo, identidad de clase). A partir de esta perspectiva, el presente artículo pretende analizar la inserción del product placement como producto estructural orgánico en la narrativa de la telenovela peruana. Nos ocuparemos concretamente del caso de la serie de televisión "Los Vílchez" estrenada el 2 de enero del 2019. Para ello, se observará particularmente la forma semionarrativa de inserción del producto en la telenovela "Los Vílchez" producida por América Tv durante el 2019. Este interés permite trabajar un nivel comercial camuflado en su trama narrativa, dicho en otro modo, el modo de inserción del hecho mercantil en los productos culturales. Se han escogido para este estudio escenas específicas de inserción del product placement en la trama para analizar las interacciones del público desde una perspectiva narrativo-semiótica.

\section{2.}

\section{Estado de la cuestión}

\subsection{Economización de la telenovela latinoamerica- na}

La telenovela es un producto audiovisual masificado, provisto de códigos culturales expresados en una axiología, narrativa y estética melodramática. Una de las exploraciones académicas más citadas sobre el trabajo de la novela en Latinoamérica se encuentra en el trabajo de Jesús Martín-Barbero De los medios a las mediaciones (1987). El trabajo de Martín-Barbero (1987) presenta al melodrama como expresión significante de modos de vivir, formas de vida y lecturas ideológicas de regiones específicas que se reconocen (diríamos mejor, son empáticas) en los relatos pre- 
sentados. De lo que nos interesa, para efectos de este artículo, son las relaciones que realiza Martín-Barbero (1987) en la relación íntima entre la telenovela y las lógicas del consumo:

\begin{abstract}
"Frente a la concepción y esa vivencia, las transformaciones operadas por el capitalismo en el ámbito del trabajo y del ocio, la mercantilización del tiempo de la calle y de la casa y hasta las relaciones más primarias, parecerían haber abolido aquella socialidad. En realidad no han hecho sino tornarla anacrónica." (p, 245)
\end{abstract}

Para Martín-Barbero (1987) se presenta la astucia (o "venganza" como lo prefiere el maestro español) de ciertas expresiones o desbordes populares como, en este caso, el relato melodramático, frente a los excesos de una sociedad mercantilizada. Las pertinencias del melodrama producen efectos de identidad en los espectadores al reconocer distintos niveles de símbolos y formas significantes culturales (Murillo \& Escala, 2013) que rehúyen de la instrumentalización económica de las relaciones sociales. Es la narración, conducto de memoria e imaginación, la que provee de sentido a la ejecución del melodrama más allá de las argucias temáticas que confrontan al pobre pauperizado y a la riqueza como objeto de deseo. Estas dramatizaciones narrativas (de 120 a 200 capítulos) exceden el tiempo cotidiano de las narrativas de productos culturales comunes, donde la rapidez y la fragmentación se convierten en productos rápidos de consumo (Adriaens \& Biltereyst, 2011).

No obstante, la lectura de la narración del melodrama, como un alejamiento mercantil o fuga cultural de las intenciones comerciales, es complicada de sostener, considerando la intimidad entre el consumo y la cultura. Dentro del desarrollo de la propia telenovela durante los noventas las temáticas sociales reivindicatorias de lo popular fueron cediendo a la comercialización, no solo de la novela misma en un mercado cada vez más global. Precisamente, son los procesos de flexibilización del mercado los que hacen de la novela un producto global a través los medios internacionales que integran significantes culturales locales en la narrativa (Adriaens \& Biltereyst, 2011). También la propia narrativa que cedía cada vez más incursiones de marcas y productos dentro de su estructura. Ya en la década de los noventa la intuición de la telenovela no solo como una expresión cultural, sino como un producto atractivo para la producción industrial y corporativa era apuntada en Latinoamérica (Caunedo, 1990). De esta manera los roles y estructuras del relato eran manipulados para lograr un éxito comercial para las marcas auspiciadoras: "El factor sentimental tiene un peso fundamental. En Venezuela por ejemplo, al comenzar la telenovela se hace una encuesta entre la población, y conforme a sus resultados, determinan la duración y alteran el final de la trama, de acuerdo con lo que quiere el público, para garantizar el éxito" (Caunedo 1990, pp. 52-53). De acuerdo a esta presentación, la narrativa ficcional de la telenovela está íntimamente ligada a las disposiciones mercantiles y a las intencionalidades publicitarias.

En el caso de la telenovela colombiana, por ejemplo, su época de destello comercial fue la década de los noventa, cuando las narrativas producidas por canales privados como Radio Cadena Nacional (RCN) y Caracol apuntan a un mercado extranjero y a una mejor difusión en plataformas digitales emergentes (Lozano \& Mendoza, 2010). Una de las novelas producidas en este intervalo de tiempo fue "Betty la fea" emitida entre 1999 y 2000 y la novela brasilera O Rei do Gado (La Pastina, 2001). Si bien la tematización del relato de esta última novela, expresó las lógicas del clasismo y superficialidad de nuestra cultura (utilizando la sátira y el sarcasmo para atravesarlas) (Echeverry, 2016), la novela contemplaba interacciones como el product placement en tanto lógica de consumo normalizadas dentro de estas narrativas. Marcas como Pantene, Orbitel, Max Factor se encontraban dentro de la propia narrativa de la novela construyendo espacios de consumo integrados a las temáticas reivindicatorias y sociales.

Este registro del estado de las telenovelas en varios países latinoamericanos marca una relevancia indudable de la producción de ficción dentro de la región. En el Perú, esta tendencia no ha marchado de manera diferente. Desde sus inicios radiales en 1958 hasta la ficción contemporánea en el formato televisivo, se ha mantenido una articulación sólida entre las temáticas propias de la originalidad de la ficción y aquellas otras exclusivas de la coyuntura, por ejemplo el narcotráfico, el terrorismo o la diferencia de clases sociales (Quiroz \& Cano, 1988). En este sentido, la narrativa de la telenovela peruana ha respon- 
dido mayormente a los procesos culturales, políticos y populares acaecidos en el país. Este es el caso de la telenovela "Natacha" (1990), donde el rol de la mujer y su representación en la ficción dentro del formato televisivo se asoció en la década de los ochenta con temáticas familiares, reactivas y maternales (Grados, 2010), mientras que actualmente, telenovelas como "Ven, baila, quinceañera" (2015-2019) reconstruyen esta representación hacia personificaciones femeninas valerosas, independientes y fortalecidas. Esta recreación de la ficción de acuerdo a sus coyunturas ha permitido comprender también su rol importante como agente de circulación de mercancías. Así, desde telenovelas populares como "Simplemente María" (1969) que impulsaron la venta de máquinas de coser (como la que la protagonista usaba) (Mateus, 2008) hasta las complejas producciones actuales que sobreviven de las intervenciones comerciales, una de ellas el product placement.

\subsection{El product placement como elemento narrativo}

Definida como una técnica comercial cuya particularidad es la de inscribirse en contenidos mediáticos masivos, el product placement encuentra un asidero especial en el desarrollo de la telenovela y su estructura melodramática. Los motivos de una reciprocidad entre el product placement y la novela son manifiestos: el producto encuentra gran respuesta en la conducta popular (awareness) después de su mención (corta) en la novela lo cual incrementa las tarifas por aparición de los productos, y la rentabilidad de la misma novela (Paluck, et ál., 2015).

Los principales estudios sobre el product placement en productos mediáticos como telenovelas o melodramas generalmente se ocupan del análisis de los efectos (positivos o negativos) en los consumidores y televidentes (Pervan \& Martin, 2002). La inserción de productos en la narrativa puede activar la intención persuasiva en televidentes y espectadores (Milfeld \& Flint, 2020). Los estudios sobre el product placement coinciden en una relación disruptiva del producto en la narrativa del producto audiovisual. En algunos casos, los usuarios buscan en la publicidad como una fuente de información parcial y menos creíble y tienden a resistir una fuerte presión publicitaria (Dias, et ál., 2017). En otros, se consigue una relación de afinidad con los consumidores, en tanto el producto encuentra lugar orgánico en una narrativa que permite a los televidentes una liberación emocional y una gratificación que les permite huir de las tensiones del espacio social de interacciones (Stern, et ál., 2005)

Otras posibilidades de análisis entienden al product placement dentro de las estrategias de comunicación y comercialización inscritas en el panorama narrativo del melodrama. En esta ruta el interés es más bien estratégico (Jung \& Childs, 2020). Desde esta perspectiva estratégica el product placement posee dos relaciones de inmersión, según las secuencias narrativas canónicas y no-canónicas (Yalán-Dongo, 2018). Según esta presentación, las narrativas canónicas de la publicidad se estructuran en cuatro secuencias: (i) secuencia inicial de carencia (ii) secuencia de la enunciación (iii) secuencia de la prueba (iii) secuencia de la solución o apoteosis. Siendo el product placement una colocación de producto. Canónicamente su estructura se relaciona con la segunda secuencia narrativa de la publicidad tradicional. El product placement en la publicidad cumple el rol de introducir el producto en algún momento de la narrativa, bajo el supuesto de que es siempre preferible mostrar cómo el consumo surge de pronto en la ficción de un relato, interactúa con los personajes de la narrativa violentando la línea orgánica del argumento del capítulo. No obstante, las estrategias narrativas no canónicas suponen dos instancias concretas (i) secuencias de objeto mundo y (ii) secuencia de continuidad. La primera busca incluir al producto de forma orgánica en el relato, relacionando sus menciones con el flujo continuo de la narrativa, implicada en el mundo de los personajes y de la temática del melodrama. La segunda continúa el relato sin limitarse por un fin o clausura que permitan al producto una futura aparición esperable (Yalán-Dongo, 2018). Las secuencias de objeto-mundo pueden ser amplificadas a través de estrategias como la omisión (se elimina un elemento en la presentación del producto para concretar que el espectador cierre el relato), la transposición (se desarrolla el relato del producto en desorden), permutación (se recontextualiza al producto en un mundo no consumista) o adición (se agrega al producto como personaje nuevo en el relato) (Scolari, 2013b). En este caso, el producto encuentra un grado de inmersión en el relato, lo que le permitiría una mayor familiaridad, credibilidad o identificación (Dias, et ál., 2017). 
La ocupación del product placement en la narrativa (específicamente en la secuencia de la prueba) exige una expectativa estratégica como parte de una decisión por parte de especialistas o coordinadores vinculados a la marca auspiciadora. Dentro de esta estrategia se pueden reconocer las siguientes: (i) prominencia (ii) mención verbal del producto, (iii) interacción entre los actores y el producto y (iv) la combinación de pistas audiovisuales relacionadas con el producto en su colocación narrativa (Van der Westhuizen \& Mulder, 2019). De esta manera, la colocación de productos en el melodrama, desde la perspectiva del marketing, observa al product placement como un elemento estructural con diversos grados de integración con la escena o la historia analizada (Jung \& Childs, 2020). Estos grados de integración determinan si el producto logra una incrustación orgánica que propicie reconocimiento y familiaridad o, lejanía y resistencia por parte de los televidentes-consumidores.

Este rechazo o aceptación del product placement tiene relación con una conducta estructural en el relato. Desde la teoría transmedia de Henry Jenkins (2008), la integración del producto puede presentarse dependiente de las estrategias narrativas de inmersión y extracción. Por una parte, la inmersión supone una relación de atracción de los consumidores al mundo de la ficción fabulado por la narrativa. Los espectadores (enunciatarios) del enunciado narrativo se ven envueltos en la narrativa sea por elementos de identificación fantástica (como el product placement invertido) o conexión emocional encontrando precisamente un escape a la realidad (Jenkins, 2008; Stern et ál., 2005). La inmersión (immersion) permite entender fenómenos como el plinking, la inmersión del consumidor, que puede abrir un camino de consumo (el consumidor detiene la pantalla para efectuar la compra). Por otra parte, la extracción (extractability) tiene que ver con un reconocimiento anómalo e intertextual de ciertos elementos incrustados en la narrativa, como trascendentes o exteriores a la inmanencia del relato (romper la cuarta pared, por ejemplo).

\section{3.}

\section{Materiales y métodos}

La presente investigación de enfoque cualitativo sostiene una metodología hermenéutica en tanto busca identificar la colocación del product placement como elemento estructural narrativo orgánico en la telenovela peruana. Su diseño es el estudio de caso (Creswell, 2013) como parte de una investigación de campo intensiva que pretende recuperar datos concentrados particulares desde una perspectiva interpretativa (Arias, 2012). Para ello se atenderá al caso de la telenovela peruana producida por América Televisión y la productora ProTv Producciones "Los Vílchez", de 138 episodios, emitida desde enero a abril de 2019, en el horario de 20:15 a 21:15. La elección del caso se debe a dos consideraciones. En primer lugar, la construcción narrativa de la telenovela ha endosado diversas tensiones coyunturales acaecidas en el Perú, desde la igualdad de género y el empoderamiento femenino, hasta las referencias a temáticas de corrupción, migración, vacancia presidencial, conflictos entre el ejecutivo y legislativo, los cuales permiten ser contenidos orgánicos para los espectadores y, por lo tanto, propicios para la inmersión comercial. En segundo lugar, la narrativa es relevante dentro de la producción de telenovelas peruanas considerando que es un spin-off de la telenovela "Ven, baila, quinceañera" sostenida desde el 2015 en el Perú y considerada como uno de los productos televisivos de gran audiencia histórica en el Perú (Fermi, 6 de Marzo de 2019). Se procedió al análisis de los capítulos concretando la atención en el product placement de las marcas Ricocat, Milo y Head \& Shoulders. La recopilación de la data se efectuó mediante la aplicación de los instrumentos y técnicas de la semiótica generativa (Greimas \& Courtés, 1982). Desde la perspectiva semiótica, como técnica de investigación (Sayago, 2014) se precisa considerar una delimitación del corpus de estudio y la textualización del objeto de estudio para la efectuación de una descripción exhaustiva (correlación entre la inducción y la deducción en el análisis) y adecuada. El corpus es paradigmático, es decir, es el estudio de las variantes de presentación del product placement sostenidos por el relato de la telenovela "Los Vílchez". Asimismo, la textualización pretende formar narrativamente al caso -la telenovela- en tanto conjunto material que manifieste el sentido del discurso que 
será estudiado. Finalmente, se busca la representatividad partiendo de la saturación, es decir, la aplicación del modelo de análisis partiendo de un segmento intuitivamente elegido para agotar su información. Se aplicará el modelo generativo específicamente en su aplicación narrativa: la interpretación a través de técnicas de la sintaxis y semántica narrativa que atienden los devenires del product placement como actante y su singularidad en la cadena del relato.

\section{4 .}

\section{Resultados y discusión}

Desde la perspectiva del análisis del discurso, se suele considerar a la narrativa como un momento estructural dentro del proceso de significación, que implica la conversión de ciertas valoraciones y significaciones sociales en programas del relato enunciado. De esta manera, la telenovela conserva un discurso cuyos valores derivan de toda una axiología cultural que nutre al relato (referencias espaciales y figuratividades de los actantes, que son familiares al consumidor-espectador). Para la semiótica generativa (Greimas \& Courtés, 1982), tanto el nivel narrativo como el fundamental, de los valores y las unidades significantes, poseen una sintaxis definida por la disjunción y la conjunción, es decir, por la aceptación y el rechazo de las unidades narrativas y semánticas. En este sentido, los juegos semánticos de aceptación y rechazo modelan las historias y sus acciones presentando arquitecturas narrativas como juegos de interacción entre los actantes de las historias en el melodrama o la telenovela cómica. Estas sintaxis se encuentran presentes en el caso de la telenovela "Los Vílchez".

Las interacciones de los personajes en la narrativa pasan de un rechazo a priori de los personajes principales (por su carácter, por sus motivaciones, deseos) respecto a sus distintos objetos de deseo (emocionales, personas concretas, situaciones, etc.) hasta una resolución y aceptación programada hacia un final feliz de la historia, es decir, la conjunción de los personajes con estas metas. Esta sintaxis narrativa es más o menos prevista por el espectador desde el comienzo del relato: se concreta el romance de "Julia Cabezas" con "Vicente León" (Bicho), se logra la boda - simultánea- de "María Elena" y "Viviana" con "Esteban" y "Johnny", respectivamente. Esta composición narrativa es reconocida en la telenovela "Los Vílchez" es conservada también por el relato publicitario, en la medida que ambos se presentan como productos culturales con pretensión masiva y, por tanto, reconocida por una totalidad consumidora. En este sentido, podemos relacionar esta sintaxis narrativa con las cuatro secuencias importantes en la estructura canónica del relato publicitario (Yalán-Dongo, 2018) que se ajustan en semejanza a la presentación de la narrativa de la novela "Los Vílchez".

\section{Tabla 1}

Homologación narrativa del relato de la telenovela y las secuencias narrativas de la publicidad canónica.

\begin{tabular}{|l|l|l|l|l|}
\hline & Situación de carencia & Situación de enunciación & Situación de la prueba & \multicolumn{1}{|c|}{$\begin{array}{c}\text { Situación de la } \\
\text { plenitud }\end{array}$} \\
\hline $\begin{array}{l}\text { Estructura } \\
\text { narrativa } \\
\text { canónica } \\
\text { de la tele- } \\
\text { novela }\end{array}$ & $\begin{array}{l}\text { Presentación de los } \\
\text { actantes (Julia, María } \\
\text { Elena, Viviana) dis- } \\
\text { juntos de sus objetos } \\
\text { de deseo en el relato. }\end{array}$ & $\begin{array}{l}\text { Presentación de las posi- } \\
\text { bles motivaciones de los } \\
\text { actantes, principales pro- } \\
\text { blemáticas a enfrentar. }\end{array}$ & $\begin{array}{l}\text { Se prueban las fortalezas } \\
\text { del personaje (el poder } \\
\text { del amor, valentía, ho- } \\
\text { nestidad, etc.) frente a a } \\
\text { los conflictos. }\end{array}$ & $\begin{array}{l}\text { Presentación de la } \\
\text { aceptación final de } \\
\text { los personajes y su } \\
\text { motivación final } \\
\text { realizada. }\end{array}$ \\
\hline $\begin{array}{l}\text { Estructura } \\
\text { narrativa } \\
\text { canónica } \\
\text { de la pu- } \\
\text { blicidad }\end{array}$ & $\begin{array}{l}\text { Presentación de ac- } \\
\text { tantes carentes del } \\
\text { objeto de deseo (pro- } \\
\text { ducto) }\end{array}$ & $\begin{array}{l}\text { Presentación de los ac- } \\
\text { tantes que comunican } \\
\text { cómo solucionar la ca- } \\
\text { rencia al personaje prin- } \\
\text { cipal. }\end{array}$ & $\begin{array}{l}\text { Se prueban las fortalezas } \\
\text { del producto frente a so- } \\
\text { lucionar las carencias del } \\
\text { consumidor. }\end{array}$ & $\begin{array}{l}\text { Presentación del } \\
\text { objeto de deseo } \\
\text { alcanzado por el } \\
\text { personaje-consu- } \\
\text { midor. }\end{array}$ \\
\hline
\end{tabular}


El cuadro anterior muestra las homologaciones a nivel del relato, entre la narrativa canónica del relato de la telenovela y la publicidad, coincidiendo cada una en estos cuatro momentos que oscilan entre la carencia-rechazo hasta la plenitud-aceptación: "Las relaciones entre sus personajes se construyen a partir de las tensiones relacionadas con paradigmas sobre el amor-desamor, la pobreza-riqueza y maldad-bondad, con el fin de interpelar moralmente al televidente" (Lozano \& Mendoza, 2010, p. 10). Es dentro de esta homologación que pretendemos pensar al product placement como momento que responde a una lógica de consumo que se adhiere con pretensiones orgánicas a la narrativa de la telenovela para comunicar un mensaje comercial que generalmente se encuentra orientado a la funcionalidad del producto, es decir, a su valoración práctica y utilitaria de la mercancía (Floch, 1993; Semprini, 1995). Asimismo, según el análisis desarrollado, no solo se reconocen presencias físicas del producto (product placement) incrustadas en diversos momentos del relato de la telenovela, sino también presencias de la marca a través de logotipos o cromatismos (brand placement) que refuerzan un reconocimiento mercantil (formal, simbólico) en el público televidente. En ambos casos la exposición temporal es corta (short-lived) desde un punto de vista narrativo ( $\mathrm{Pa}-$ luck, et ál., 2015).

En su presentación tradicional dentro de la narrativa, el product placement emerge en lo que, partiendo de los estudios de Henry Jenkins (2008), se ha denominado como narrativa de extracción. Una narrativa de extracción se produce cuando un elemento generalmente ajeno al desarrollo orgánico del relato, en este caso ajeno a la ficción, irrumpe para provocar un relato alterno que extrae a los sujetos espectadores de la narrativa. La irrupción finalmente revela la ficción y enrarece el relato de la telenovela que, antes de la emergencia del product placement, se encontraba construyendo un efecto de hacer-parecer verdad. En su presentación en la narrativa de "Los Vilchez", el product placement no solo aparece anunciando el corte comercial que cerraría una primera parte de la historia, sino tiende a aparecer aprovechando los momentos de reposo del contenido narrativo principal, sean conversaciones entre los actantes o en situaciones que serían más calmadas que la narrativa principal de la telenovela, como por ejemplo, escenas de transición entre una secuencia y otra (prominencia).

\section{Figura 1}

Presencia de producto cerrando un bloque del capítulo (Marca Ricocat)

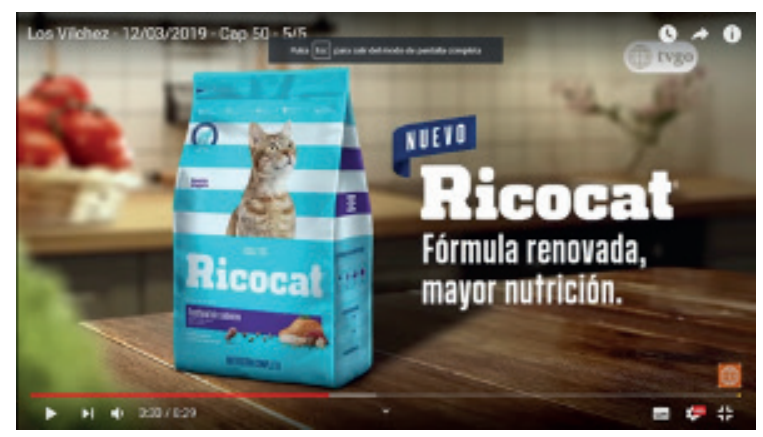

Nota: Captura de pantalla telenovela "Los Vílchez" Capitulo 50. Tomada de (América Televisión - Novelas (13 de marzo de 2019)

La aparición de la marca Ricocat se presenta como un product placement de prominencia (Van der Westhuizen \& Mulder, 2019), una secuencia breve que funciona como transición y reposo que aprovecha los datos ofrecidos por la trama para mantener al espectador atento a los detalles funcionales del producto, en este caso, el desempeño nutritivo del alimento para gatos. En este sentido, el reposo y la detención narrativa generan una inercia intensiva provocada por la escena anterior que logra endosarse a la aparición del producto otorgándole brillo axiológico. Solo así el hecho comercial adquiere notoriedad y singularidad. No obstante, no es la única figura de transición en el relato de "Los Vílchez", también se construye un product placement (y un brand placement cuando se tratan de empresas servicios) menos desligado del escenario del relato y de las atmosferas que sostienen las interacciones entre los actantes. Es el caso de la marca Milo. 


\section{Figura 2}

Presencia de producto en la transición entre escenas (Marca Milo)

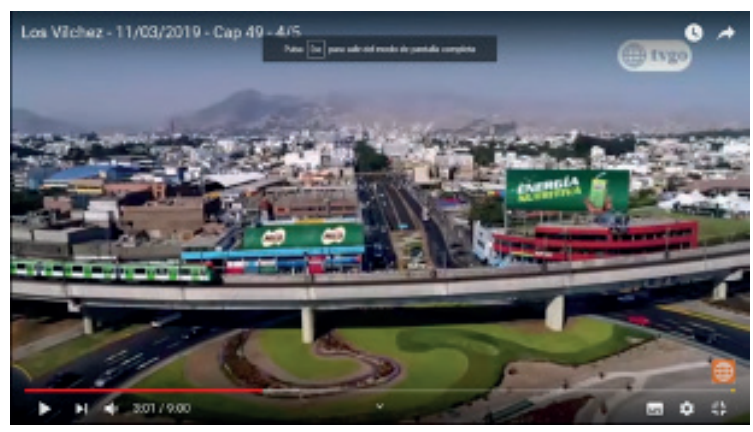

Nota: Captura de pantalla telenovela "Los Vílchez" Capitulo 49. Tomada de (América Televisión - Novelas, 12 de marzo de 2019)

En este segundo caso, la marca Milo aparece no fuera del relato de la telenovela, sino como parte de esta, específicamente manteniendo una relación espacial que permite embragar o motivar la aparición del tiempo presente desde donde se enuncia el relato. El product placement de transiciones posee una primera relación con el espacio, en este caso, con uno social, habitado, humano y de convivencia. Su pertinencia no solo es familiarizar al espectador con los ambientes de su propio día a día, sino acentuar el efecto de verosimilitud del propio relato televisivo. Finalmente, una presentación recurrente y relacionada al tipo de product placement de interacción entre los actores y el producto (Van der Westhuizen \& Mulder, 2019), es el caso de Head \& Shoulders.

\section{Figura 3}

Presencia de producto desarrollando sus funcionalidades con uno de los personajes (Marca Head \& Shoulders)
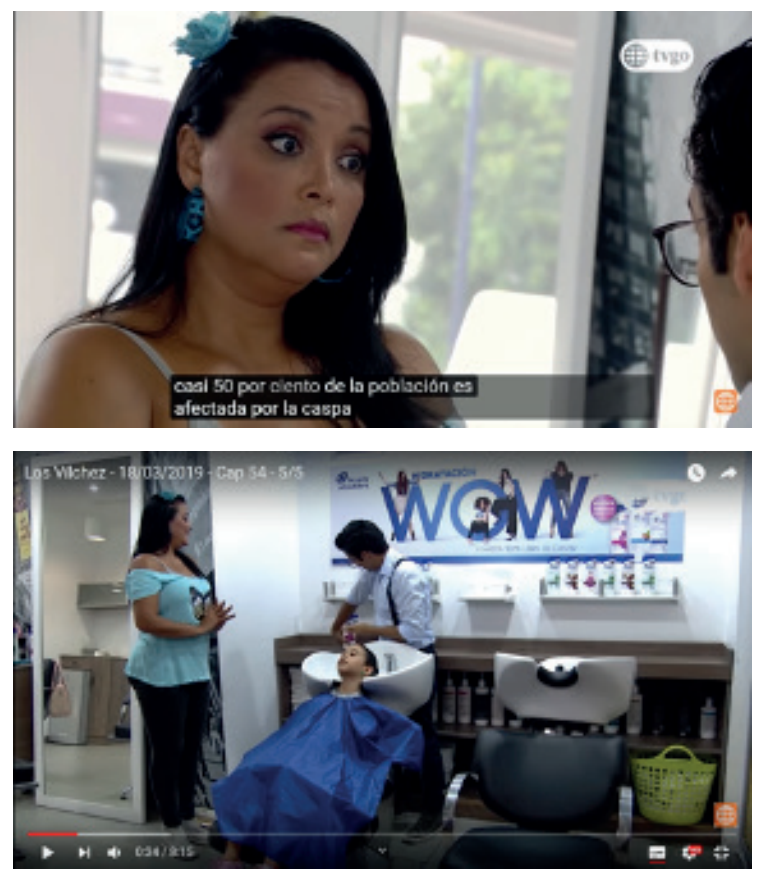

Nota: Captura de pantalla telenovela "Los Vílchez" Capitulo 54. Tomada de (América Televisión - Novelas, 19 de marzo de 2019)

En esta escena uno de los personajes interactúa directamente con una personificación del producto, quién es finalmente el que introduce, explica e informa al actante y al enunciatario -el espectador- sobre las bondades funcionales del producto de manera no tan desprendida de la ficción, en este caso de las motivaciones del actante del relato. Con esta presentación se comprenden los tipos de inserción del product placement de Van der Westhuizen y Mulder (2019) (i) prominencia en la transición entre escenas (ii) mención verbal del producto antes de los cortes comerciales y la (iii) interacción entre los actores y el producto. Dicho esto, el product placement retoma la inercia de la ficción creada para insertar un contenido no ficcional con el propósito de crear una respuesta sensible y cognitiva en los potenciales consumidores. Sin embargo, la teoría narrativa del product placement se ha enfrentado a una objeción por parte de las teorías narrativas de la comunicación y la pre- 
sión de los anunciantes por integrar sutilmente el producto (inbound marketing). Según autores como Scolari (2013a), las narrativas de extracción generan un rechazo cada vez más acentuado por parte de los consumidores hacia la emergencia publicitaria. La ponderación negativa hacia la irrupción de una narrativa ficcional orgánica concluye con la participación narrativa de los espectadores (disengagement) y la presunta incredulidad hacia este momento del consumo -el product placement- que quiebra el relato. Afirma Paluck (2015):

"Other media scholars who predict small to null population-level media effects note the "noise" of the present-day media environment, meaning both the vast array of available media programming available to viewers and the numerous distractions that accompany a typical media viewing setting. In our study, it is notable that the messages and resulting product placement scenes make up a small percentage of the total airtime and are incidental to the broader themes of the telenovelas". (p. 13)

Ante estas irrupciones, nuevamente partiendo de Henry Jenkins (2008), se pretende concentrar el análisis hacia otro tipo de narrativas que complican el estudio sobre la telenovela y su relación con el consumo. Llamaremos a este tipo 'narrativas de inmersión'. Este tipo de arquitectura del relato permite que los elementos adscritos no desarrollen una posición extraña a la narrativa sobre la cual se pretende plantar o inscribir el product placement. Desde este punto de vista, el producto deja de ser un momento de emergencia que quiebra la ficción para más bien ser parte orgánica de ella; los personajes usan el producto sin necesidad de promocionarlo comercialmente, el producto asume no un rol de mero brague de la enunciación, sino de elemento actancial de la estructura del relato. En suma, el producto puede devenir tanto en un actante más de la narrativa como en una espacialización o en una temporalidad necesaria para la construcción del relato del melodrama. Dicho esto, sumamos a los tipos de inserción de Van der Westhuizen y Mulder (2019) los reconocidos aquí en la telenovela "Los Vílchez": la programación actancial del producto y la espacialización del producto.

\section{Figura 4}

\section{Programación actancial del producto}

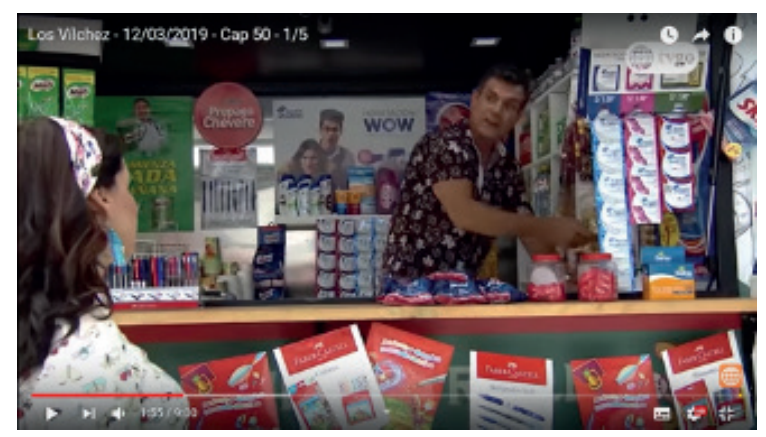

Nota: Captura de pantalla telenovela "Los Vílchez" Capitulo 50. Tomada de (América Televisión - Novelas, 12 de marzo de 2019)

En esta escena la programación actancial del producto permite relacionar a tres personajes dentro del escenario narrativo, "María Elena", "Esteban" y la tienda de éste último personaje. Al asumirse como actante, la tienda guarda sus propios roles figurativos y temáticos (/inamovible/, /económico/, / abastecimiento/, /superación/, /emprendimiento/), adquiere una vida en el relato que acompaña las incidencias y ocurrencias de los personajes. Por otra parte, la espacialización del producto es una organización discursiva que sirve como marco para sostener los desarrollos narrativos. En ambos casos, el product placement se convierte en figura ingénita de la ficción al formar parte de la narrativa, sea como un personaje más (la tienda del 'Gauchito') del relato de la serie, o como una figura de espacialización del mismo (paneles que componen el paisaje visual de la residencial donde transcurren los eventos narrativos de la novela). 
Figura 5.

La espacialización del producto

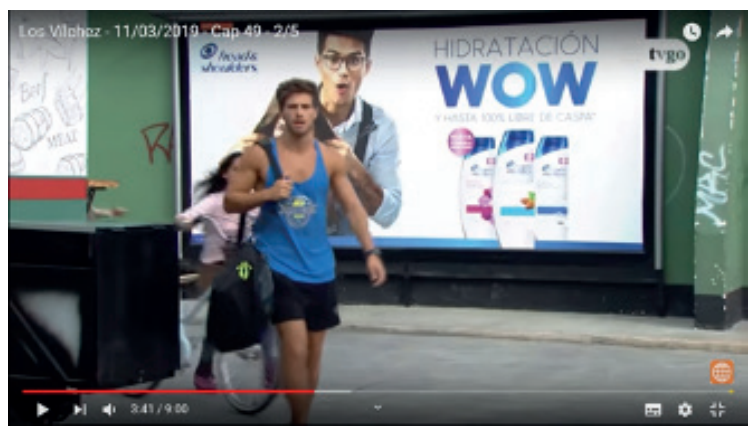

Nota: Captura de pantalla telenovela "Los Vílchez" Capitulo 49. Tomada de (América Televisión - Novelas, 12 de marzo de 2019)

Desde una perspectiva semiótica, la espacialización es uno de los componentes de la producción de un discurso, relacionada con la localización, los puntos territoriales del afuera-adentro, y la programación espacial del propio relato (Greimas \& Courtés, 1982). Para los estudios de semiótica contemporánea (Zilberberg, 2006), las figuras de espacialización se encuentran atravesadas por niveles no solo extensivos (medibles: distancias, referencias) sino intensivos (afectivos) que proveen a los espacios de al menos tres niveles: espacios volitivos, espacios demarcativos y espacios fóricos. Los espacios volitivos serán aquellos espacios de la dirección que muestran una abertura y cierre (un personaje que en la ciudad cierre- puede encontrar espacios de abertura), los espacios demarcativos apostarán por la posición, sea de exterioridad o de la interioridad (donde el interior de una casa, por ejemplo, puede ser atraída por el afuera de un barrio o quinta como tendencia de la intrusión), mientras que los espacios fóricos serán aquellos de los impulsos de movimientos y reposos (desplazamientos del espacio). De esta manera, la presencia del producto dentro de la narrativa se encontrará determinada por los saltos emotivos del relato del capítulo: (i) acompañando, cuando los personajes discuten de singularidades mínimas de la vida cotidiana de las acciones, o (ii) memorizando, en tanto el relato emotivo no puede resguardarse en los espacios interiores que usualmente comportan los conflictos de los personajes, sino que es expuesto en la exterioridad del espacio público de interacción. La intensificación del relato posee diversas dinámicas de mercantilización de la telenovela cuando reconocemos las dos inserciones o colocaciones del product placement en la historia del relato televisivo. Si bien la aplicación tradicional del product placement podía ser reconocida e identificada rápidamente en el relato por su naturaleza extractiva e intencionalmente comercial, construcciones como la espacialización del producto y su programación actancial, aquí identificadas, logran la inmersión y normalización publicitaria, permiten la eficiencia comercial pero también la naturalización del consumo en la telenovela.

5.

\section{Conclusión}

Como un producto masificado, la telenovela se somete a las determinaciones comerciales que la mercantilizan. Se ha tratado de presentar al product placement como momento narrativo que expresa esta mercantilización, con ánimos de aprovechar las familiaridades e identificaciones que producen actores y acciones del melodrama o la telenovela cómica. Partiendo del caso "Los Vílchez" se ha identificado no solo un uso intrusivo del product placement, sino también se han identificado modos de presencia orgánica del producto en el relato de la telenovela con el fin de amplificar los modos de colocación del objeto mercantil en la narrativa cultural. En esta ruta se han detectado presentaciones actanciales y espacio-temporales del product placement como garantes de inmersión en el relato al ya no formar parte externa de los eventos narrativos de la telenovela, sino más bien colocarse dentro del sintagma fluidificado del relato, orgánico a los eventos, paisaje visual de las escenas no-comerciales. Estos formatos de presentación nos animan a pensar los diversos modos de inserción de la mercancía en la circulación narrativa de los productos culturales, es decir, los diversos grados (de extensidad e intensidad) de colocación del producto en el relato, comprometidos a su vez con diversas intenciones (y precios) del anunciante. Pero también, nos permiten preguntarnos sobre las estrategias de camuflaje capitalista en las enunciaciones sociales, la recreación mercantil del espacio y su axiología de consumo presentada como eslabón normalizado del día a día. 
6.

\section{Referencias}

América Televisión - Novelas (12 de marzo de 2019) Los Vílchez - 11/03/2019 - Cap 49 - 4/5 [Video]. YouTube. https://www.youtube.com/watch?v=X3BlQvijwW4

América Televisión - Novelas (13 de marzo de 2019) Los Vílchez - 12/03/2019 - Cap 50 - 5/5 [Video]. YouTube. https://www.youtube.com/watch?v=Sq8YpE VwSbs\&t $=248 \mathrm{~s}$

América Televisión - Novelas (19 de marzo de 2019) Los Vílchez - 18/03/2019 - Cap 54 - 5/5 [Video]. YouTube.

https://www.youtube.com/watch?v=UMi tIWebHA

América Televisión - Novelas (12 de marzo de 2019) Los Vílchez - 12/03/2019 - Cap 50 - 1/5 [Video]. YouTube.

https://www.youtube.com/watch?v=G3uTCZr7KYg

América Televisión - Novelas (12 de marzo de 2019) Los Vílchez - 11/03/2019 - Cap 49 - 2/5 [Video]. YouTube.

https://www.youtube.com/watch?v=VVGJhbu65bU

Arias, F. (2012). El proyecto de investigación: Introducción a la metodología científica (6ta ed.). Editorial Episteme, C.A.

Adriaens, F., \& Biltereyst, D. (2011). Glocalized Telenovelas and National Identities: A "Textual Cum Production" Analysis of the "Telenovelle" Sara, the Flemish Adaptation of Yo soy Betty, la fea. Television \& New Media, 13(6), 551-567. https://doi.org/10.1177/1527476411/427926
Alfaro, S. R. (2016). ¿Aprender español de las telenovelas?: un aporte desde la perspectiva de receptores rumanos. Revista de Lenguas Modernas, 25, 411-423.

https://doi.org/10.15517/RLM.VoI25.27715

Caunedo, S. (1990) El maratón de las telenovelas. La universidad: Revista de la universidad de El Salvador, 1, 51-54. http://revistas.ues.edu.sv/index.php/launiversidad/ article/view/869

Creswell, J. W. (2013). Qualitative inquiry and research design: Choosing among five traditions (3rd ed.). Thousand Oaks, CA: SAGE Publications, Inc.

Dias, J. A., Dias, J. G., \& Lages, C. (2017). Can negative characters in soap operas be positive for product placement? Journal of Business Research, 71, 125-132 https://doi.org/10.1016/j.jbusres.2016.10.010

Echeverry, J. (2016) Propuesta teórica para abordar la telenovela en cuanto producto cultural. Caso de estudio: Yo soy Betty, la fea. Maguaré, 30(1) pp. 45-69

https://revistas.unal.edu.co/index.php/maguare/ article/view/62885

Fermi, G. V. (6 de Marzo de 2019). Entre spin off y narrativa transmedia: la serie juvenil peruana Ven Baila Quinceañera. [presentación de paper] Congreso Internacional de Cultura Visual. Paris, Francia.

https://conferences.eagora.org/index.php/ imagen/VISUAL-2020

Floch, J.-M. (1993). Semiótica, marketing y comunicación: bajo los signos, las estrategias. Paidós.

Grados, M. (2010). Una mirada al consumo de telenovelas en el Perú desde el funcional estructuralismo. La Colmena, (3), 15-21.

http://revistas.pucp.edu.pe/index.php/ lacolmena/article/download/9264/9679 
Greimas, A. J. \& Courtés, J. (1982). Semiótica. Diccionario razonado de la teoría del lenguaje. Gredos.

Jung, E., \& Childs, M. (2020). Destination as Product Placement: An Advertising Strategy to Impact Beliefs and Behavioral Intentions. Journal of International Consumer Marketing, 32(3), 178-193.

https://doi.org/10.1080/08961530.2019.1662355

Jenkins, H. (2008) Convergence Culture. La cultura de la convergencia de los medios de comunicación. Paidós.

Lozano, F.J. \& Mendoza, M. I. (2010). Aproximación semiótica a los pregenéricos de las telenovelas colombianas. Opción: Revista de Ciencias Humanas y Sociales, (61), 9-22.

https://produccioncientificaluz.org/index.php/ opcion/article/view/6478

La Pastina, A. C. (2001). Product Placement in Brazilian Prime Time Television: The Case of the Reception of a Telenovela. Journal of Broadcasting \& Electronic Media, 45(4), 541-557. https://doi.org/10.1207/s15506878jobem4504_1

Mateus, J. C. (2008). El mito de la pantalla que educa. Televisión y educación en el Perú: tensiones y posibilidades. La mirada de telemo, (1), 1-10. https://hdl.handle.net/20.500.12724/3857

Martin-Barbero, J. (1992). Televisión y melodrama. Tercer Mundo.

Milfeld, T., \& Flint, D. J. (2020). When brands take a stand: the nature of consumers' polarized reactions to social narrative videos. Journal of Product \& Brand Management. Vol. ahead-ofprint No. ahead-of-print. https://doi.org/10.1108/JPBM-10-2019-2606
Murillo, S. y Escala, L. (2013). De Betty, la fea a Ugly Betty. Circulación y adaptación de narrativas televisivas. Cuadernos.info, 33, 99-112. https://doi.org/10.7764/cdi.33.531

Pervan, S. J., \& Martin, B. A. (2002). Product placement in US and New Zealand television soap operas: an exploratory study. Journal of Marketing Communications, 8(2), 101-113. https://doi.org/10.1080/13527260210152382

Paluck EL, Lagunes P, Green DP, Vavreck L, Peer L, Gomila R (2015) Does Product Placement Change Television Viewers' Social Behavior? PLOS ONE, 10(9) 1-18.

https://doi.org/10.1371/journal.pone.0138610

Quiroz, M. T., \& Cano, A. M. (1988). Los antecedentes y condiciones de la producción de telenovelas en el Perú. Estudios sobre las culturas contemporáneas, 2(5), 187-221.

https://www.redalyc.org/pdf/316/31620507.pdf

Sayago, S. (2014). El análisis del discurso como técnica de investigación cualitativa y cuantitativa en las ciencias sociales. Cinta de moebio, (49), 1-10. http://dx.doi.org/10.4067/ $\underline{\text { S0717-554X2014000100001 }}$

Semprini, A. (1995) El marketing de la marca. Una aproximación semiótica. Paidós.

Scolari, C. (2013a) Narrativas transmedia. Cuando todos los medios cuentan. Grupo Planeta.

Scolari, C. (2013b). Lostology: Transmedia storytelling and expansion/compression strategies. Semiotica, 195, 45-68.

http://dx.doi.org/10.1515/sem-2013-0038

Stern, B. B., Russell, C. A., \& Russell, D. W. (2005) Vulnerable women on screen and at home: soap opera consumption. Journal of Macromarketing, 25(2), 222-225. http://dx.doi.org/10.1177/0276146705280717 
Van der Westhuizen, E., \& Mulder, D. (2019). Guidelines to enhance recall and recognition of product placement strategies. Communitas, 24. http://dx.doi.org/10.18820/24150525/Comm.v24.5

Yalán-Dongo, E. (2018) Semiótica del consumo: Una aproximación a la publicidad desde sus signos. Universidad peruana de ciencias aplicadas.

http://dx.doi.org/10.19083/978-612-318-160-4

Zilberberg, C. (2006) Semiótica tensiva. [Traducción: Desiderio Blanco]. Universidad de Lima. 